\title{
Research of new methods for quality air control after massive explosions in the open mine industry
}

\author{
Natalya Shvaher*, and Tatyana Komisarenko \\ Kryvyi Rih National University, Department of labor protection and civil security, 11 Vitalii Matusevych Str., Kryvyi Rih, 50027, \\ Ukraine
}

\begin{abstract}
The aim of this study is to analyze the existing methods to determine the presence of harmful substances in the open pit atmosphere after massive explosions, and to develop a method of measuring the gas composition of the atmosphere using unmanned aerial vehicle (UAV). Existing methods of controlling the whole open pit atmosphere and its individual sections do not meet safety requirements. The main disadvantages are that workers should be present at danger zone and they are exposed at risk of poisoning by harmful gases. In addition, these methods require considerable time for delivery and analysis of samples in the laboratory, and the results contain significant measurement errors. Therefore, it is necessary to develop a methodology to determine the presence of harmful substances in the open pit atmosphere after massive explosions using UAV device, and conduct analytical research of signal dissemination to UAV control in the air. It was established that the implementation of the proposed method will allow to get quickly reliable data on the chemical composition of atmosphere in the explosion areas. It is possible to carry out the control measurements during mining operations without their interruption and without people presence in the dangerous area which allows to increase safety.
\end{abstract}

\section{Introduction}

Proven reserves of the iron ore for Kryvorizkyi Iron Ore Basin are one of the largest in Europe, about 32.2 billion tons, with an iron content in the ore from $22-65 \%$ [1-4]. Mining works are carried out using open and underground methods. It should be noted that minerals containing iron from 22 to $36 \%$ are exploited by open pit mining and minerals containing iron from 48 to $65 \%$ by underground mining [5-8]. Underground methods are traditionally designed using chamber system or using massive ore body collapse methods by deep wells, which reduces iron ore containing from $65 \%$ to $58-62 \%$. It should be noted that the production cost of underground mining is much higher than open pit methods (by 2-3 times) [9-11].

To reduce production costs in underground mining works the system design is continuously improved by increasing the iron content in the mined ore mass $(60-$ 62.5 ) which allows to reduce the difference in the cost of production by 1.8-2.7 times [12-14].

Significant reduction in the cost of iron ore underground mining is possible by use of imported equipment and use of emulsion explosives "Ukrainit" [15-16]. To improve conditions of mining ore extraction, it is proposed to increase the diameter of the holes up to $250 \mathrm{~mm}$, which significantly reduces the extraction cost. However, this enhancement will significantly worse the mine air, and with the present mechanization level, it will increase the cost of ventilation.

Thus, the open pit mining is currently providing a significant level of mechanization, productivity and economic performance, but has a negative impact on the environment, namely on the air quality.

Massive explosions in quarries are accompanied by the formation of powder-gas cloud of dust 0.030$0.19 \mathrm{~kg} / \mathrm{m}^{3}$, carbon monoxide - 60-95 $1 / \mathrm{kg}$ and nitrogen oxides $-3.5-7 \mathrm{l} / \mathrm{kg}$. Hazardous substances formed during an explosion reach high overtime concentrations in the open pit mine air. Therefore there is a negative impact on the workers and residents of adjacent areas health [17]. It should also be noted that even after required time of ventilation in the working area, blasted rock still releases toxic gases. After mass explosion, content of carbon monoxide into the blasted rock is $4-5 \%$, and nitrogen oxides up to $0.06 \%$. A significant danger to workers represent remaining after the explosion dust and gas, which exude from the blasted rocks and pollute the air of the blasted blocks.

Today the most common way in Kryvbas quarries to determine the presence of hazardous substances (carbon monoxide $\mathrm{CO}$, carbon dioxide $\mathrm{CO}_{2}$, methane $\mathrm{CH}_{4}$, nitrogen oxide $\mathrm{NO}$, nitrogen dioxide $\mathrm{NO}_{2}$ ) and of the dust after an explosion is a measurement carried out by a group of specialized employees directly on-site. Atmosphere measurements are conducted by pumping the air through the samplers in different parts of the blasted blocks. Then air samples are delivered to a

Corresponding author: knu.shwager@gmail.com 
laboratory, which decides on the admission of workers in the explosion area [18-21].

The main drawback of this method is the presence of workers in the danger zone and therefore a risk of poisoning by harmful gases and dust. In addition, this method requires considerable time for delivery and analysis of samples in the laboratory. The results of measurements by this method unreliable because the sampling is conducted at the ground level of blasted rocks.

The method makes impossible determining of the atmosphere changes at several meters height and also during mining works, where gas emissions continue from the blasted rocks. [22-23]

Another way to control harmful substances is a method developed by Research Institute for Safety and Ecology in the Mining and Metallurgy Industries [24], it consists in the installation on a distance of 20-30 m from the blasted blocks border of hydro-mechanical and electromechanical devices for air sampling. After the explosion, under the influence of seismic waves occurs triggering of these devices. When block access is allowed, an analysis of gas concentration is conducted. Sampling takes place in special containers.

A well-known is a way of determining the presence of harmful substances, using a discrete measuring of the atmosphere chemical composition on the set trajectory around the geometric center of the blasted rocks. In the blasted blocks is installed on the ground a set of individual devices to sampling the air quality, consisting on placing them in concentric ellipsoid conventional lines (trajectories) around the geometric center of the blasted rocks. Ellipsoid lines form should take into account the direction and speed of wind [25]. Each atmosphere sampling block consists of a number of devices for sampling, which is equal to the number of sampling points accordingly to the regulations for the air quality control. Once installed, the sampling units are powered and remote controlled from a safe place. After the explosion and appearance of the gases, the device is periodically activated remotely according to adopted regulations for air quality control in the atmosphere. After the sampling, the samples from these devices are delivered to a laboratory in order to analyze the chemical composition of the atmosphere air.

The disadvantage of this method is its low reliability because there are a number of sampling units that are placed in the explosion area on the ellipsoid trajectory, therefore the devices may be damaged by pieces of blasted rock. In addition, this method is highly labor intensive and requires highly skilled and specially trained workers. During samples recovery from the devices, the workers are exposed at risk of poisoning by harmful gases and by dust. The method doesn't allow to quickly determine the changes of air chemical composition, because of the blasted rock emissions of harmful gases and dust, after the loading operations. Moreover, in case of wind direction change, the results will be distorted.

Another way to control the quality of atmosphere air, which is similar in terms of technical realization and obtained results to the one described above, is to control the atmosphere gas composition after an explosion, using unmanned aerial vehicle (UAV), which carries out a discrete measuring of the chemical composition of air in the trajectory around the geometric center from the blasted rock at some given points. UAVs are equipped with portable gas analyzer with gas and dust detectors, onboard computer, electronic altimeter and navigation. The trajectory of UAV has the form of horizontal rectangles, geometric center of which coincides with the geometric center of the blasted rocks area. A portable gas analyzer automatically saves the measurement at a preset time and transmits the obtained results to on-board computer. A signal from UAV is transmitted to the ground station computer. Using navigator, it is possible to track and record the trajectory of UAV at the fixed height from the ground which is set and controlled by an electronic altimeter [26, 27].

One of the most important characteristics is the autonomy of action and maximum range of a UAV. Compared to the other methods of control, such as direct sampling or aircraft use, the UAVs autonomy is crucial.

\section{Methods}

The area of mass explosions in opencast mines of Kryvbas depends on the deposit geological characteristics, for example, the width of blasted rocks area may start from 20 meters and the length starts from $200 \mathrm{~m}$ [26].

In this study, we consider several options for mass explosion area in order to compare the data and to identify the necessary autonomy. In addition, it is necessary to add the distance from the safe place to the work area. This distance taken from $500 \mathrm{~m}$ to $1000 \mathrm{~m}$ (in the worst case).

UAV must conduct exploration and analysis of the air after a massive explosion, its schematic trajectory of flight is shown on the Fig. 1.

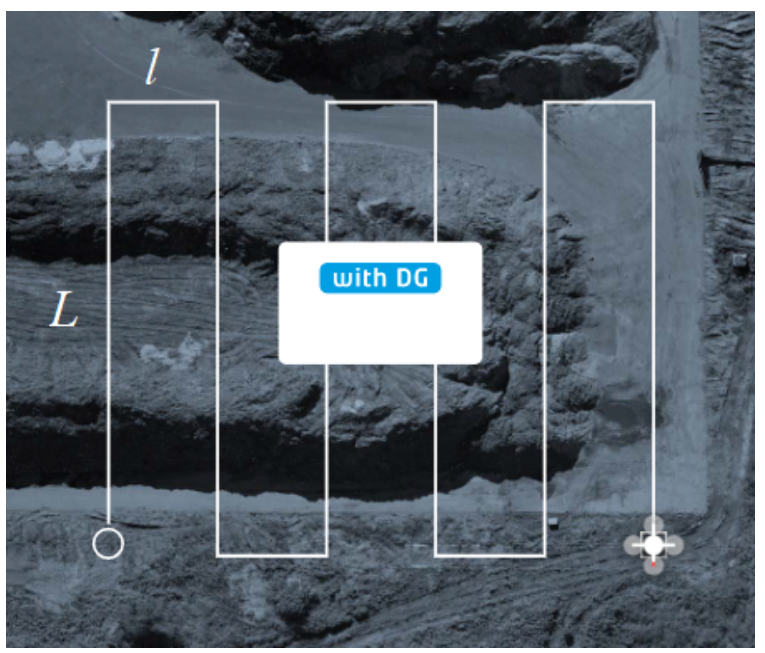

Fig. 1. Schematic trajectory of UAV movement to measure air quality after massive explosion.

For parameters of the block, we consider the block length $A=300 \mathrm{~m}$ and block width $B=30 \mathrm{~m}$, the total length of trajectory flown over by $\operatorname{UAV}(P)$ is calculated 
below using a pitch $l=5 \mathrm{~m}$.

$$
\begin{gathered}
P_{\text {measures }}=(A / 1 \cdot L)+(A / 1 \cdot 1), \mathrm{m} \\
=P(300 / 5 \cdot 30)+(300 / 5 \cdot 5)=2100 \mathrm{~m}
\end{gathered}
$$

It is also necessary to take into account the distance from the shelter to the mass explosion area, in this case $P_{\text {shelter }}=2 \times 1000 \mathrm{~m}=2000 \mathrm{~m}$. Generally, UAVs must travel a distance of at least $3 \mathrm{~km}$ in order to carry out measurements in the mass explosion area.

The velocity of the UAV will be different at each stage of trajectory, UAV velocity during the flight from shelter to work area $V_{\text {shelter }}$ will be different from the velocity during the measurements $V_{\text {measures. The distance }}$ from the shelter to the work area the UAV can flight at a speed $V_{\text {shelter }}=8-10 \mathrm{~m} / \mathrm{s}$, while for the measurement, UAV is limited to a maximum speed $V_{\text {measures }}$ at $2-3 \mathrm{~m} / \mathrm{s}$ to ensure the measuring performance.

Thus, we get:

$$
T_{\text {total }}=P_{\text {shelter }} / V_{\text {shelter }}=2,100 / 8=263 \mathrm{~s},
$$

taking 5 minutes.

$$
T_{\text {measures }}=P_{\text {measures }} / V_{\text {measures }}=1000 / 2=500 \mathrm{~s},
$$

taking approximately 9 minutes

Thus, autonomy of UAVs must be at least 14 minutes, under ideal operating conditions (with no wind). Therefore, to choose UAVs, it is necessary to consider models with an autonomy more than 30 minutes, and with a cruising speed of $8-10 \mathrm{~m} / \mathrm{s}$ in order to ensure reliable operations without any risk to lose the equipment. It is also necessary to consider a model with autonomous action radius of $2-3 \mathrm{~km}$.

The career's air after a mass explosion is quite heterogeneous. Let's consider a spreading beam with a wavelength $\lambda=12 \mathrm{~cm}$. We also consider the forces acting on dust particle as shown on the figure below (Fig. 2):

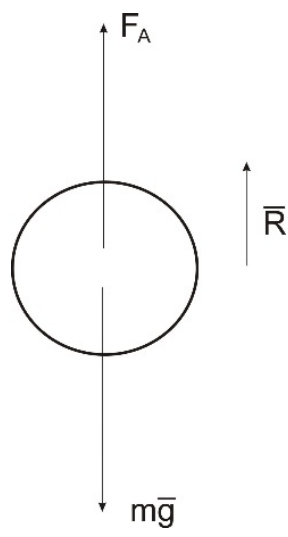

Fig. 2. The forces acting on dust particles in the air.

Power Archimedes: $F_{\mathrm{A}}=M_{\mathrm{a}} \cdot g$, where $M_{\mathrm{a}}$ particle mass of displaced air. The air's density is $\rho_{0}\left(\mathrm{~kg} / \mathrm{m}^{3}\right)$ and to simplify we use a spherical particle with radius $r$. In this case:

$$
F_{A}=\frac{4}{3} \cdot \pi \cdot r^{3} \rho_{0} \cdot g
$$

$R$ - is the resistance of air (N). According to Stokes' law:

$$
R=6 \cdot \pi \cdot \mu \cdot r \cdot U
$$

where $\mu-$ is air's viscosity, $P_{\mathrm{a}} \cdot \mathrm{s} ; U-$ is particle's velocity $(\mathrm{m} / \mathrm{s})$.

In the case of linear movement during the particle's fall if the forces are equal, we can find the velocity of dust particles fall:

$$
U=\frac{2}{9} \cdot \frac{\rho-\rho_{0}}{\mu} \cdot r^{2} \cdot g
$$

From this expression, it follows that after the explosion, the particles with a large radius and high density fall fast. So after some time, it will remain in space the dust particles with a size which will satisfy the condition $r<\lambda(12 \mathrm{~cm})$.

In this regard, these particles can be called "the smallest" (Fig. 3). To these particles we can apply the Rayleigh-Mie theory.

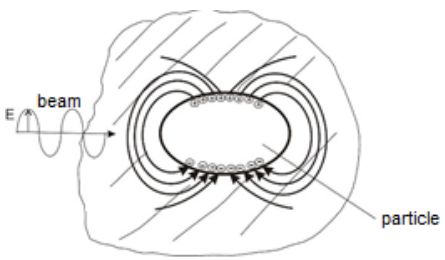

Fig. 3. The interaction of electromagnetic waves with the "smallest particle".

In this case, the functions included in the number of scattering coefficients $a_{\mathrm{N}}$ and $b_{\mathrm{N}}$, can be expanded in power series and keep only a few firsts members:

$$
\left\{\begin{array}{c}
\Psi_{1}(Z)=\frac{Z^{2}}{3}-\frac{Z^{4}}{30} ; \Psi^{\prime}(Z)=\frac{2 \cdot Z}{3}-\frac{2 \cdot Z^{3}}{15} \\
\xi_{1}(Z)=-\frac{i}{Z}-\frac{i Z}{2}+\frac{Z^{2}}{3} ; \xi_{1}^{\prime}(Z)=\frac{i}{Z^{2}}-\frac{i}{2}+\frac{2 \cdot Z}{3} \\
\Psi_{2}(Z)=\frac{Z^{3}}{15} ; \Psi_{2}^{\prime}(Z)=\frac{Z^{2}}{5} \\
\xi_{2}(Z)=-\frac{i^{3}}{Z^{2}} ; \xi_{2}^{\prime}(Z)=\frac{i}{Z^{3}}
\end{array}\right.
$$

Using this approach, the first four amplitude coefficients are equal:

$$
\left\{\begin{array}{c}
a_{1}=-\frac{i \cdot 2 \alpha^{3}}{3} \cdot \frac{m^{\prime 2}-1}{m^{\prime 2}+2}-\frac{i \cdot 2 \alpha^{3}}{5} \cdot \frac{\left(m^{\prime 2}-2\right)\left(m^{\prime 2}-1\right)}{\left(m^{\prime 2}+2\right)^{2}}+ \\
+\frac{4 a^{6}}{9}\left(\frac{m^{\prime 2}-1}{m^{\prime 2}+2}\right)^{2} ; \\
b_{1}=-\frac{i \alpha^{5}}{45}\left(m^{2}-1\right) ; \\
a_{2}=-\frac{i \alpha^{5}}{15} \cdot \frac{m^{\prime 2}-1}{2 m^{2}+3} \\
b_{2}=0
\end{array}\right.
$$

Expansion for the amplitude scattering coefficients of higher order containing the members of order $\alpha_{7}$ and above. If $\left|m^{\prime}\right| \cdot \alpha<1$, therefore $\left|b_{1}\right|<\left|\alpha_{1}\right|$

Taking this assumption, we can leave only the first partial electric wave. 


$$
a_{1}=-i \cdot \frac{2 \cdot \alpha^{3}}{3} \cdot \frac{m^{\prime 2}-1}{m^{\prime 2}+2}
$$

In this case, the weakening efficiency factor will be determined by the expression:

$$
\begin{aligned}
& Q_{0}=4 \alpha \operatorname{Im}\left\{\frac{m^{\prime 2}-1}{m^{\prime 2}+2} \cdot\left[1+\frac{\alpha^{2}}{15}\left(\frac{m^{\prime 2}-1}{m^{\prime 2}+2}\right) \cdot \frac{m^{\prime 4}+27 m^{2}+38}{2 m^{\prime 2}+3}\right]\right\}+ \\
& \frac{8}{3} \alpha \operatorname{Re}^{4}\left(\left|\frac{m^{\prime 2}-1}{m^{\prime 2}+2}\right|^{2}\right) .
\end{aligned}
$$

To determine the scattering efficiency factor, we use the following formula:

$$
Q_{p}=\frac{8}{3} \cdot \alpha^{4}\left|\frac{m^{\prime 2}-1}{m^{\prime 2}+2}\right|^{2} .
$$

If

$$
\begin{gathered}
\left|m^{\prime}\right| \cdot x<1 \\
Q_{0}=4 \alpha \cdot \operatorname{Im}\left(-\frac{m^{\prime 2}-1}{m^{\prime 2}+2}\right)=4 \frac{2 \pi r m_{0}}{\lambda_{0}} \cdot \operatorname{Im}\left(-\frac{m^{2}-1}{m^{\prime 2}+2}\right), \\
Q_{p}=\frac{8}{3} \cdot \frac{\left(2 \cdot \pi \cdot r \cdot m_{0}\right)^{4}}{\lambda^{4}}\left|\frac{m^{\prime 2}-1}{m^{\prime 2}+2}\right|^{2} .
\end{gathered}
$$

To determine the scattering coefficients $K_{0}$ and $K_{p}$ in this approach we use the following expression:

$$
\begin{aligned}
& K_{0}=\frac{6 \cdot \pi \cdot m_{0}}{\lambda_{0}} \operatorname{Im}\left(-\frac{m^{\prime 2}-1}{m^{\prime 2}+2}\right), \\
& K_{p}=\frac{4 \cdot \pi \cdot m_{0}}{\lambda_{0}} \cdot \alpha^{3} \cdot\left|\frac{m^{\prime 2}-1}{m^{\prime 2}+2}\right|^{2} .
\end{aligned}
$$

In the transition to the dielectric constant $m=n-i x$;

$$
m^{2}=\left(n^{2}-x^{2}\right)-i 2 \cdot \pi \cdot x=\varepsilon_{1}-i \varepsilon_{2},
$$

We obtain from the following formula:

$$
\begin{gathered}
K_{0}=\frac{6 \cdot \pi \cdot m_{0}}{\lambda_{0}} \operatorname{Im}\left(-\frac{\varepsilon_{1}-m_{0}^{2}-i 2 \cdot n \cdot x}{\varepsilon_{1}+2 \cdot m_{0}^{2}-i 2 \cdot n \cdot x}\right) \\
K_{p}=\frac{4 \cdot \pi \cdot m_{0}}{\lambda_{0}} \cdot \frac{\left(2 \cdot \pi \cdot r \cdot m_{0}\right)^{3}}{\lambda_{0}^{3}}\left|\frac{\varepsilon_{1}-m_{0}^{2}-i 2 n x}{\varepsilon_{1}+2 m_{0}^{2}-i 2 n x}\right|^{2} .
\end{gathered}
$$

Thus, the problem of the remote beam spread is resolved. With a weak dependence of the complex refractive index material particles $\mathrm{m}$ on the wavelength $\lambda$ the attenuation coefficient is: $K_{0} \approx 1 / \lambda_{0}$, and $K_{\mathrm{p}} \approx 1 / \lambda_{0}{ }^{4}$.

The main task of the UAV is to obtain a reliable data on the atmosphere chemical composition at sites located in the area of the mass explosion. This data should include the air composition at different altitudes without people's presence and also to provide rapid control of the atmosphere chemical composition during rock loading operations [28-30].

The technical result of this proposed model allows to dramatically reduce the atmosphere control time, to obtain a reliable data after the mass explosion, and during the loading operations and exclude the participation of specially trained workers in dangerous area. Therefore, this method allows to increase a safety of workers.
According to the proposed method, measuring of the atmosphere gas composition is conducted using an unmanned UAV unit (Fig. 4), which is equipped with independent engines 1, portable gas analyzer 2, dust detectors 3 , on-board computer 4, equipment to store the measurement data 5, electronic altimeter 6 and navigator 7 .

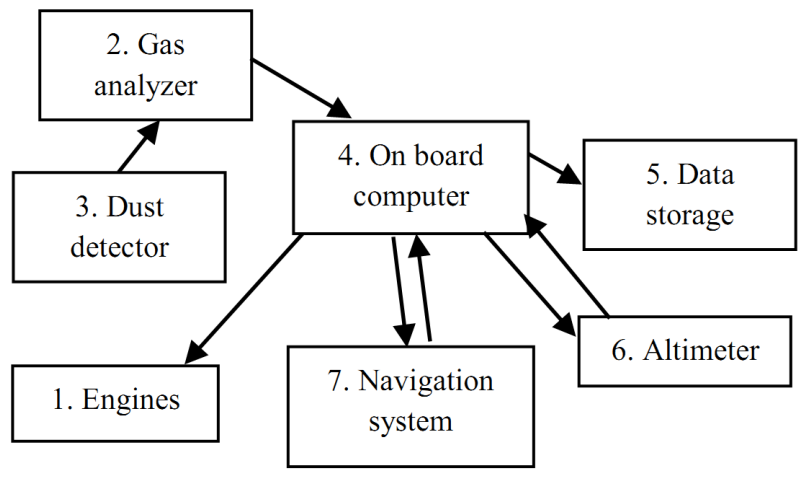

Fig. 4. Schematic diagram of the UAV (unmanned aerial vehicle).

The on-board computer generates a radio signal and transmits it to the ground computer. Movement trajectories of UAV (Fig. 5) have the form of horizontal rectangles 9, with a set of atmosphere measurement points 10 . The length and width of trajectories 9 cover the entire surface of blasted rock and the geometric center 11 of the trajectories 9 which coincides with the geometric center 12 of the blasted rock.

The parameters of smaller concentric rectangular trajectories 13 are determined based on the adopted regulations to control the atmosphere. The UAV movement trajectories 9 include the different heights $\mathrm{H}_{1}$, $\mathrm{H}_{2}, \mathrm{H}_{3}$ from the surface.

To ensure reliable measurements of particles, the UAV is equipped with additional camera by which is conducted aerial photographing during the gas composition measuring.

The calculation of the harmful substances concentration at massive explosion is carried out by the authors $[31,32]$, it allows to conclude that the concentration of carbon monoxide, nitrogen oxides and dust in the atmosphere exceeds the maximum permitted level. This creates a critical situation because of air pollution in the working area.

The intensity of air pollution depends on the properties and state of the rock, weather conditions, equipment and technology, efficacy of methods of dust and harmful gases control.

In this regard, the level of dust and of air pollution in the workplace may vary widely. Significant impact on career's air quality has the composition and moving direction of air flows, which in many cases determines the amount of contaminants. To solve this problem, it has been proposed a method to control by the UAV the gas composition in carrier's atmosphere after mass explosion. 

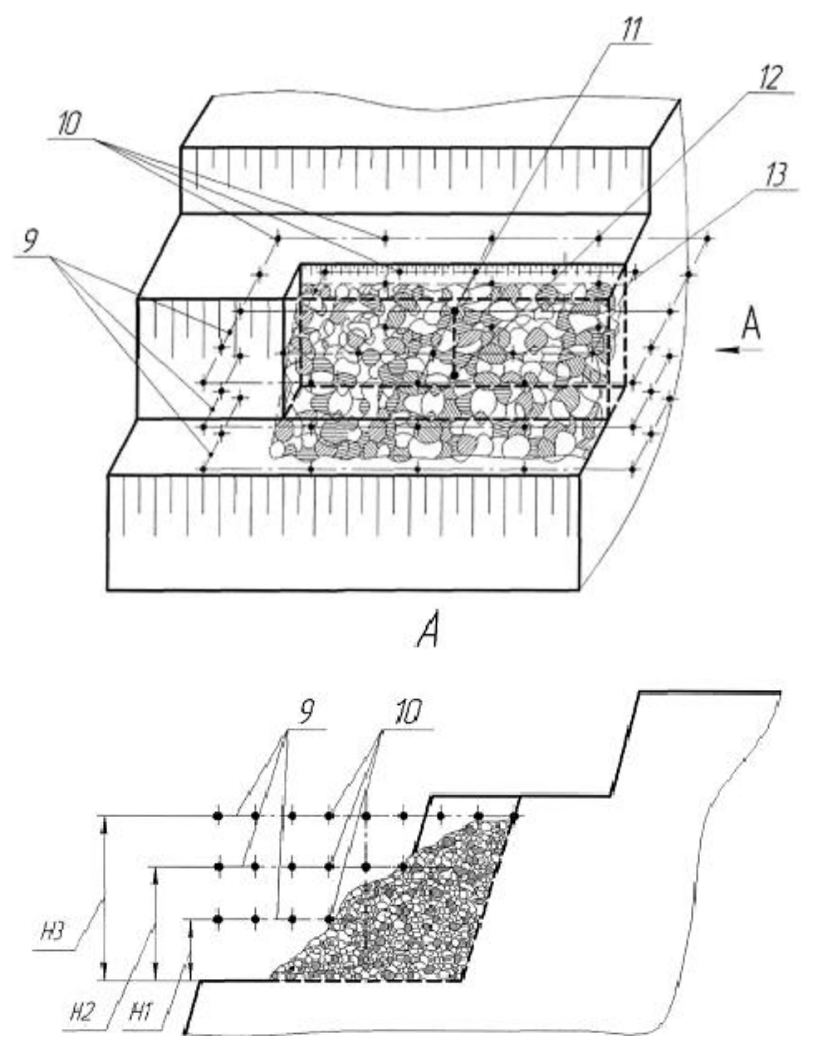

Fig. 5. UAV movement trajectory [26].

\section{Results and discussion}

Implementation of the proposed method to control the career's atmosphere after the mass explosion will allow to quickly obtain a reliable data on the air chemical composition in mass explosion areas without people's presence, and without interruption of mining operations.

This method to control the career's atmosphere and the gas composition after mass explosion, including discrete measurements of chemical composition on the trajectory around the geometric center of the blasted rock at given points, consists by measurement of gas composition using UAV, whose is equipped by a portable gas analyzer with gases and dust detectors, an on-board computer, an electronic altimeter and a navigation. UAV trajectory has the form of horizontal rectangles, which geometry center coincides with the geometric center of the blasted rock area. UAV use a portable gas analyzer which automatically saves the current measurement at preset time, with the transmission of the obtained results from on-board computer.

Measurements of the atmosphere chemical composition are done at the different heights from the surface. UAV is equipped with additional cameras by which is conducted an aerial photographing during the measuring of the atmosphere gas composition; the measurements data is compared to the coordinates at given points during UAV's flight path.

Thus, the use of UAV for determining the concentration of harmful gases after massive explosions allows to avoid the human presence in the dangerous area and to obtain quickly the information about air quality (the total time to collect and process the information would not exceed 1 hour). The disadvantages of the method is the relatively high cost of the equipment.

\section{References}

1. M.I. Stupnik, V.O. Kalinichenko, S.V.Pysmennyi, O.V. Kalinichenko, Naukovyi Visnyk Natsionalnoho Hirnychoho Universytetu 4, 21-27 (2018). doi:10.29202/nvngu/2018-4/4

2. V. Kalinichenko, S. Pysmennyi, N. Shvaher, O. Kalinichenko, Selective underground mining of complex structured ore bodies of Kryvyi Rih Iron Ore Basin. E3S Web of Conferences 60, 00041 (2018). doi:10.1051/e3sconf/20186000041

3. N. Stupnik, V. Kalinichenko, S. Pismennyi, E. Kalinichenko, Features of underlying levels opening at "ArcellorMittal Kryvyi Rih" underground mine, in New Developments in Mining Engineering 2015: Theoretical and Practical Solutions of Mineral Resources Mining (2015), pp. 39-44

4. N. Stupnik, V. Kalinichenko, S. Pismennyi, Pillars sizing at magnetite quartzites room-work, in Mining of Mineral Deposits (2013), pp. 11-15

5. M.I. Stupnik, V.O. Kalinichenko, O.V. Kalinichenko, I.O. Muzika, M.B. Fed'ko, S.V. Pismennyi, Metallurgical and mining industry 7, 377-383 (2015)

6. M. Petlovanyi, O. Kuzmenko, V. Lozynskyi, V. Popovych, K. Sai, P. Saik, Review of mineral formations accumulation and prospects of their developing in mining industrial regions in Ukraine. Mining of Mineral Deposits 13/1, 24-38 (2019). doi:10.33271/mining13.01.024

7. M.B. Fedko, I.O. Muzyka, S.V. Pysmennyy, O.V. Kalinichenko, Naukovyi Visnyk Natsionalnoho Hirnychoho Universytetu 1, 37-41 (2019). doi:10.29202/nvngu/2019-1/20

8. M.B. Fedko, V.A. Kolosov, S.V. Pismennyy, Y.V. Kalinichenko, Naukovyi Visnyk Natsionalnoho Hirnychoho Universytetu 4, 79-84 (2014)

9. M. Petlovanyi, V. Lozynskyi, S. Zubko, P. Saik, K. Sai, Rudarsko Geolosko Naftni Zbornik 34/1, 8391 (2019). doi:10.17794/rgn.2019.1.8

10. M. Stupnik, V. Kolosov, S. Pysmennyi, K. Kovbyk, Selective mining of complex stuctured ore deposits by open stope systems. E3S Web of Conferences 123, 01007 doi:10.1051/e3sconf/201912301007

(2019).

11. M. Stupnik, V. Kolosov, V. Kalinichenko, S. Pismennyi, Physical modeling of waste inclusions stability during mining of complex structured deposits, in Progressive Technologies of Coal, Coalbed Methane, and Ores Mining (CRC Press, London, 2014), pp. 25-30. doi:10.1201/b17547 
12. N.I. Stupnik, M.B. Fedko, V.A. Kolosov, S.V. Pismennyy, Naukovyi Visnyk Natsionalnoho Hirnychoho Universytetu 5, 21-25 (2014)

13. V. Lozynskyi, P. Saik, M. Petlovanyi, K. Sai, Z. Malanchuk, Analytical Research of the StressDeformed State in the Rock Massif around Faulting. International Journal of Engineering Research in $\begin{array}{llll}\text { Africa } & 35, & 77-88 & \text { (2018). }\end{array}$ doi:10.4028/www.scientific.net/jera.35.77

14. N. Shvaher, T. Komisarenko, S. Chukharev, S. Panova, Annual production enhancement at deep mining. E3S Web of Conferences 123, 01043 (2019). doi:10.1051/e3sconf/201912301043

15. S. Pysmennyi, D. Brovko, N. Shwager, I. Kasatkina, D. Paraniuk, O. Serdiuk, Eastern-European Journal of Enterprise Technologies 5/1(95), 33-45 (2018). doi:10.15587/1729-4061.2018.142483

16. M. Stupnik, V. Kalinichenko, B. Rymarchuk, S. Pysmennyi, M. Fedko, E. Kalinichenko, Technology audit and production reserves 6/1(44), 29-35 (2018). doi:10.15587/2312-8372.2018.152055

17. T. Kalybekov, M. Sandibekov, K. Rysbekov, Y. Zhakypbek, Substantiation of ways to reclaim the space of the previously mined-out quarries for the recreational purposes. E3S Web of Conferences 123, 01004 (2019). doi:10.1051/e3sconf/201912301004

18. A. Drizhenko, Vidkriti girnichi roboti (NGU, Dnipropetrovsk, 2014)

19. V.Yu. Tishuk, M.F. Yevdokimenko, M.M. Guba, Yu.I. Gorobec, P.K. Kuzmenko, Ohorona praci ta navkolishnogo seredovisha na pidpriyemstvah girnicho-metalurgijnogo kompleksu. $\mathrm{Zb}$. nauk. prac 9, 85-98 (2007)

20. P.V. Beresnevich, V.I. Dengub, V.G. Nalivajko, Changes in dust concentration from a massive explosion in a quarry. FTPRPI 2, 100-103 (1987)

21. M.I. Prosandyeyev, L.M. Kozlova, Ekologiya i prirodokoristuvannya 14, 143-160 (2011)

22. L.I. Antoshkina, N.N. Belyaev, L.F. Dolina, Air pollution: Modeling, forecasting, protection (Nauka i osvita, Dnipropetrovsk, 2008)

23. V. Mihajlov, P. Beresnevich, Dust control in ore mines (Nedra, Moscow, 1981)

24. V.Y. Tyshuk, V.Yu. Evdokimenko, Zbirnyk naukovykh prats NGU 28, 158-164 (2007)

25. A.E. Azarkovich, L.G. Bolhovitinov, A.S. Zverev, The method of monitoring the gas composition of the atmosphere after explosions. AS SSSR 1798649, K1. G01N 1/22, Zayavl. 25.09.90. Opubl. 28.02.93. Byul. No 8.

26. A.S. Aralkin, T.A. Komissarenko, Method of controlling the composition of the atmosphere after mass explosion. Patent Ukrayini No 118217, byul. No. 14, 25.07.2017

27. D. Rysbekov, T. Huayang, M. Kalybekov, K. Sandybekov, Y. Idrissov, G. Zhakypbek, Bakhmagambetova, Application features of the surface laser scanning technology when solving the main tasks of surveying support for reclamation. Mining of Mineral Deposits 13/3, 40-48 (2019). doi:10.33271/mining 13.03.040

28. V.Y. Tyshuk, Suchasni resursozberigayuchi tehnologiyi girnichogo virobnictva 1/2010 (5), 127132 (2010)

29. V. Tron, O. Tsokurenko, D. Paraniuk, I. Haponenko, Formation of the adaptive fuzzy model of the rock geological structure for exploratory drilling. E3S Web of Conferences 123, 01037 (2019). doi:10.1051/e3sconf/201912301037

30. V. Bondarenko, I. Kovalevs'ka, K. Ganushevych (eds.), Progressive Technologies of Coal, Coalbed Methane, and Ores Mining (CRC Press, London, 2014), pp. 333-339

31. V.E. Kolesnik, A.A. Yurchenko, A.A. Litvinenko, A.V. Pavlichenko, Ways and means of enhancing the environmental safety of mass explosions in iron ore quarries by dust factor (Litograf, Dnepropetrovsk, 2014)

32. A.V. Zvyaginceva, A.Y. Zavyalova, Analysis of the main technological and engineering measures aimed at reducing dust and gas emissions during mass explosions on the carts of a mining and processing plant. Geliogeofizicheskie issledovaniya (2015) 